\title{
Call me, later! Patients' experiences of Swedish healthcare call-back services and access to healthcare
}

\author{
Magnea Unnarsdottir ${ }^{1}$, Henry Ascher ${ }^{1,2}$, Jonas Hermansson ${ }^{1}$, Louise Danielsson*1,2 \\ ${ }^{1}$ Angered Hospital, Sweden \\ ${ }^{2}$ Section of Epidemiology and Social Medicine, Institute of Medicine, Sahlgrenska Academy, University of Gothenburg, Sweden
}

Received: May 3, 2018

DOI: $10.5430 /$ jha.v7n5p8
Accepted: June 25, 2018

Online Published: June 28, 2018

\begin{abstract}
Objective: Despite the wide use of telephone call-back services in Swedish healthcare, there has been little research on how it affects patients. This study explores individual experiences of a call-back service, concentrating on barriers to healthcare, and healthcare-seeking behavior.

Methods: The study was conducted at Angered Hospital and Angered Primary Care Rehabilitation Center in Gothenburg, Sweden. Ten informants, 28-82 years old, who had used the call-back service participated in interviews about their experience of the call-back service. Thematic analysis was used to analyze data from the interviews.

Results: Three themes were identified in the analysis: (1) features and functions of the call-back service; (2) the call-back service as a barrier to or facilitator of healthcare; and (3) adjustments to the call-back service. Most informants were content with the call-back function. Negative experiences were related to language difficulties and the length of time allowed during the phone call. Lack of available appointments and telephone access were problems reported. Informants suggested a longer time frame for calls, longer opening hours regarding telephone access, more language and voicemail options, and the possibility of speaking to a person.

Conclusions: Informants in this study mostly had a positive impression of seeking healthcare using call-back services. Barriers related to language and time frame for calls could be explored in larger studies. The results from this explorative study suggests that a combination of approaches - with other options added to the call-back services - might increase equal access to health care. The use and effects of call-back services warrant further investigation.
\end{abstract}

Key Words: Call-back service, Telephone service, Access to healthcare, Healthcare barrier, Qualitative research

\section{INTRODUCTION}

Healthcare systems based on primary care are beneficial for optimal use of resources and to reduce barriers regarding access to healthcare, as exemplified in the Nordic countries by the relatively low prevalence of major non-communicable diseases compared to other European countries. ${ }^{[1]}$ Economic barriers to healthcare are considered low in Sweden, and users of healthcare services are usually content with the care that they receive. However, waiting times and lack of timely doctors' appointments are considered to be some of the most important barriers to healthcare in Sweden. ${ }^{[2]}$

Due to the waiting time at many primary care facilities, individuals tend to seek healthcare elsewhere, such as in emergency departments (EDs). ${ }^{[3,4]}$ Difficulties in navigating the health care system, different illness perceptions and lack of appointments in primary care are major reasons why individu-

\footnotetext{
*Correspondence: Louise Danielsson; Email: louise.danielsson@vgregion.se; Address: Section of Epidemiology and Social Medicine, Institute of Medicine, Sahlgrenska Academy, University of Gothenburg, Sweden.
} 
als seek nonurgent care at EDs. ${ }^{[3,4]}$ Locatelli and co-workers (2015) showed that limitations in telephone access to healthcare resulted in calls to healthcare often being postponed and that individuals are more likely not to seek care, to use drop-in appointments at primary care facilities, or to pay unnecessary visits to EDs. ${ }^{[5]}$

In Sweden, healthcare appointments in specialist and primary care are often booked over the telephone and many healthcare facilities have integrated the use of a call-back service, whereby the individual seeking care leaves his/her contact details in order for the healthcare facility to call back. The call-back service is suggested to increase telephone availability in general practice. ${ }^{[6]}$

The call-back service is usually a web based service ${ }^{[7]}$ for managing incoming telephone calls. Based on data on the opening hours, type of incoming calls, and the scheduled staff, the service calculates the approximate time when the patient will be called back. The service suggests flexible service, no missed calls, no queueing, more effective calls and a less stressful work environment for health care staff. ${ }^{[7]}$

The call back system functions in the following way. When a patient calls the center, an interactive voice asks the patient to dial his/her personal identity number and telephone number. The interactive voice gives the patient an approximate time when he or she will be called back. If this is not a suitable time, the patient can choose a later call-back. The call-back service can end the phone call if no choice is made within a given time; this varies between healthcare facilities, and some offer an option to go back. Some facilities offer the option to leave a short voice message or to navigate the system in languages other than Swedish, most often English. An example of a patient using the call-back service is presented in Table 1 below.

Table 1. Example of the call-back service

A woman suffering from a bad cough dials the number to the health care center to book an appointment with the GP.
Interactive voice: Welcome to the health care center. For information in English press 2 . If you suspect serious acute illness, for
example chest pain, problems with breathing or signs of stroke, call emergency112 instead. You will now have four options. If you
want to cancel a booking, press 1. If you want to renew a prescription, press 2 . If you want medical advice or book an appointment,
press 3 . If you want to record a voice message, press 4 . If you want to hear the options again, press 5.
The woman presses 3 on her phone.
Interactive voice: Enter your personal identity number, and then press \# (hash sign).
The woman enters her number using the phone digits.
Interactive voice: Enter the telephone number you want us to use for the call-back, and then press \# (hash sign).
The woman enters her telephone number using the phone digits.
Interactive voice: You have given the following telephone number: (repeats number). If this is correct, press 1. If this is incorrect,
press 2.
The woman presses 1 on her phone.
Interactive voice: You will be called back at approximately 11:20 today. If you want a later call back, press 2. Otherwise, please
hang up and we will get back to you.

The first contact with healthcare is essential to ensure a wellfunctioning primary care system. ${ }^{[8]}$ It has been suggested that great burden is put on the patients to drive calls forward and to achieve service in health care. ${ }^{[9]}$ The perceived helpfulness of staff when contacting health care is an important driver for patient satisfaction in primary care. ${ }^{[10]}$ The callback service is often used by healthcare in Sweden even though there is little evidence to support any possible benefits. Based on a need to critically examine routine health maintenance services, ${ }^{[11]}$ it is relevant to examine how the call-back service is perceived by the patients.

The aim of this study was to explore patients' experiences of a call-back service, focusing on the call-back service as a tool to come in contact with healthcare.

\section{METHODS}

\subsection{Design}

For this study, we used a qualitative approach guided by thematic analysis ${ }^{[12-14]}$ with semi-structured interviews. We opted for an inductive, explorative approach to enhance experience-based knowledge from the patients' standpoint. Here, the advantage of thematic analysis is that it provides an accessible, theoretically flexible, systematic way of collecting and analyzing qualitative data. ${ }^{[12]}$ The method allows different levels of interpretation of the data, semantic thematic patterns, or latent interpretations. ${ }^{[12]}$ We wanted to achieve a thematic structure that could be easily communicated, which made us concentrate on the semantic content and closeness to the informants' own words. 


\subsection{Study setting}

The study setting was northeastern Gothenburg, which has about 98,000 inhabitants. ${ }^{[15]}$ Approximately half of the in habitants are foreign born, and it is an area that is considered to be a challenge in terms of the socioeconomic, educational, and health status of the inhabitants. ${ }^{[15]}$

The multidisciplinary research team that conducted this study consisted of two physiotherapists, a paediatrician and an epidemiologist.

\subsection{Recruitment and informants}

A purposeful sample was recruited, to include individuals who could provide information that would improve our understanding of the call-back service. ${ }^{[11]}$ Six healthcare facilities in northeastern Gothenburg were contacted by e-mail regarding possible participation. The facilities were chosen with regard to differences in accessing care, e.g. drop-in facilities, in the hope that that this would lead to a broader group of informants. Two facilities agreed to participate: one local hospital and one rehabilitation center. Healthcare personnel at each facility recruited informants. To be included, informants had to be at least 18 years old and had to have used the call-back service. We concentrated on recruiting informants who were at risk regarding possible barriers to healthcare access, for example, non-native Swedish speakers and older individuals. The interviewer and main author was located at the healthcare facility during the time of recruitment to meet potential informants, to explain the study, and to answer questions.

Seventeen eligible informants agreed to participate, but seven of these did not show up for the interview. Consequently, ten informants were included in the study, six recruited from the rehabilitation center and four from the hospital. The ages of the informants ranged from 28 to 82 years. Nine of the informants were women. Swedish was the native language of six of the informants and four were non-native Swedish speakers.

\subsection{Data collection}

The interviewer (M.U.) carried out semi-structured, individual interviews with the informants at a time that was convenient to the informant, before or after his/her appointment at the healthcare facility. Informants had the opportunity to have an interpreter present during the interview, but none of them chose this alternative. Each interview lasted around 30 minutes.

The interview guide (see Table 2) was based on open questions about experiences of the call-back telephone system, the benefits and drawbacks of the system, and whether the call-back telephone system affected healthcare-seeking behavior. Informants were also asked if they would change anything with the current telephone system. To build trust in the interview situation and to be open for unexpected aspects of content, the interviews were kept flexible in that the interviewer tried to follow the informant's way of sharing his/her experiences, but returning to the guide whenever needed. Follow-up and probing questions were used to encourage richer descriptions ${ }^{[16]}$ and further explanations from the informants. Interviews were audiotaped and transcribed word-for-word afterwards in their original language by the interviewer. One interview was carried out in English and the other nine in Swedish. The transcriptions were done in English and Swedish, respectively. The interviews and transcriptions took place during January and February 2017.

Table 2. Semi-structured interview guide

\begin{tabular}{|c|c|}
\hline Questions & \\
\hline \multirow{3}{*}{ General questions } & Age of informant? \\
\hline & Informant's knowledge of the Swedish language? \\
\hline & How long has the informant been living in Sweden if not native to the country? \\
\hline \multirow{4}{*}{$\begin{array}{l}\text { Using the call-back } \\
\text { service }\end{array}$} & What are your general feelings about the call-back service? \\
\hline & What do you prefer using, a service like this or, for example, queuing? Why? \\
\hline & How do you manage when you make your call to healthcare? What is difficult/easy? Do you need assistance? \\
\hline & What is best/worst about the call-back service? \\
\hline \multirow{3}{*}{$\begin{array}{l}\text { The call-back service's } \\
\text { effects on users }\end{array}$} & Has the call-back service affected your decision to seek healthcare? How? \\
\hline & Has the call-back service affected how you seek healthcare? In what way? \\
\hline & Has the call-back service affected whether you have received healthcare? In what way? \\
\hline \multirow{2}{*}{ Adaptations } & Would you change anything about this call-back system? What? \\
\hline & Would you recommend the present system? \\
\hline
\end{tabular}




\subsection{Data analysis}

Analysis of data was conducted according to the six phases of thematic analysis. ${ }^{[11]}$ The first phase, becoming familiarized with the data, was done by reading through the transcribed interviews several times. In the second phase, initial codes, mainly based on sematic content, were generated from the data. The codes were organized using NVivo qualitative data analysis Software; QSR International Pty Ltd. Version 11, 2015. In phase three, the codes were sorted into a collection of candidate themes and sub-themes, which remained to be scrutinized further. During phase four, review of themes, the interviewer reviewed the coded data extracts forming each theme, and later how the themes reflected the dataset as a whole. Phase five, definition and naming of themes, was done in collaboration with the co-authors, identifying the essence of each theme. Sub-themes were also further defined and organized. Phase six, production of the report, was done in collaboration with the co-authors.

All codes were formed in English, and translations of extracts from interviews in Swedish were discussed with the co-authors, who are native Swedish speakers.

\subsection{Ethics}

All the informants signed a written consent form. They were informed that they could stop the interviews and withdraw from the study at any time, and that they were not required to answer all questions posed during the interview. Documents with information about the study were available in Swedish, English, Arabic, Somali, and Serbo-Croatian, which are the most common languages used in northeastern Gothenburg. The study was approved by the local ethics committee at Angered Hospital.

Table 3. Themes identified from analysis

\begin{tabular}{|c|c|c|}
\hline Themes & Sub-themes & Examples of interview extracts \\
\hline $\begin{array}{l}\text { Features and functions of the } \\
\text { call-back service }\end{array}$ & $\begin{array}{l}\text { Users need language skills and need } \\
\text { to be quick }\end{array}$ & $\begin{array}{l}\text { "You call, and then they perhaps say: 'we will call at } 9 \\
\text { o'clock' ... and it works." } \\
\text { "Basically, I just do a trial and error to when I get to the } \\
\text { point where I can understand when they are asking me for } \\
\text { my personal number or to leave a telephone number for } \\
\text { them to call me back." }\end{array}$ \\
\hline $\begin{array}{l}\text { The call-back service as a } \\
\text { barrier to or a facilitator of } \\
\text { healthcare }\end{array}$ & $\begin{array}{l}\text { Lack of resources is the problem, not } \\
\text { the call-back service itself } \\
\text { Forced to seek other ways of } \\
\text { accessing healthcare }\end{array}$ & $\begin{array}{l}\text { "It has gotten much better ... it is better than it was in the } \\
\text { nineties." } \\
\text { "...it was little over eight in the morning or maybe half } \\
\text { past and then they had already closed for the day..." } \\
\text { "Yes, I postpone calling if there is any other possibility, } \\
\text { such as taking a walk to the facility." }\end{array}$ \\
\hline $\begin{array}{l}\text { Adjustments to the call-back } \\
\text { service }\end{array}$ & $\begin{array}{l}\text { Wanting to speak to a person, not to a } \\
\text { machine } \\
\text { Improvement of access to healthcare } \\
\text { using additional options }\end{array}$ & $\begin{array}{l}\text { "...if only there was a person sitting/waiting at the } \\
\text { phone." } \\
\text { "It is reassuring that...now they know... I have left a } \\
\text { message, someone will get back to me and then they know } \\
\text { who I am, maybe." }\end{array}$ \\
\hline
\end{tabular}

\section{RESUlts}

Overall, the informants perceived the call-back service as a practical tool for seeking healthcare. Experiences of using the call-back service had a negative effect on healthcareseeking behavior for two of the informants, who postponed their calls to healthcare facilities or used other means of seeking care. The following three themes were identified in the analysis, describing the thematic content of the informants' experiences: (1) features and functions of the call-back service; (2) the call-back service as a barrier to or facilitator of healthcare; and (3) adjustments to the call-back service. The themes included seven sub-themes. The structure and content of themes and sub-themes are presented below and summarized in Table 3.

\subsection{Features and functions of the call-back service}

This theme involved the informants' experiences of how they managed to use the call-back service, and their practical and emotional concerns about the functionality of the call-back service.

\subsubsection{A practical alternative, when it works}

Six informants reported that they were content with how the call-back service worked for them. Dialling their numerical information was not considered to be problematic, and they 
appreciated having the option of choosing the time for the call-back. Four informants were discontent with the call-back service: these informants had experienced trouble directly related to practical functions or related to a combination of function and availability. The informants described the callback service as being a practical but somewhat unreliable option. For example, one informant was satisfied with dialling numerical information and with managing the different steps in the call-back service routine, but became frustrated when this effort had not resulted in a booked appointment, because of closed phone lines:

"When I dial my personal identity number and all that, then they will call me back... but it's getting to that point that's difficult.”

One informant also described that the call-back service was simply something that had to be used to obtain healthcare, and that it had worked adequately:

"Also, you get used to it."

\subsubsection{Users need language skills and need to be quick}

Two informants described how the call-back service featured a multiple-choice function that allowed them to "choose their direction" in the call-back service. This function was described as difficult being for these two informants who had language or memory problems. One informant with limited knowledge of Swedish had trouble in using the call-back service since this person did not understand what to choose and when to dial in numbers for authentication. An older informant ( $>80$ years) stated that the length of time provided for each step of the call to healthcare was not sufficient. Sometimes this informant had difficulty in remembering the options given during the presentation of choices, which was stressful and led to lack of time when dialling and choosing direction. Two informants reported that the call-back service ended their phone call automatically after a few seconds if they did not manage to make their choice or dial their numbers within the time frame allowed. When this happened, they had to make a new call and start all over again. This is a quote from an informant who had experienced such problems:

"You get too little time... that is how it is. It is too short a time, and it has happened to me a couple of times that my phone call has ended. Most importantly it's the numbers and such... It goes fast... and I'm too slow."

Limited language skills were sometimes a problem because some facilities only offered Swedish when using the callback service. This resulted in a feeling of insecurity in one informant, about whether or not the call had been registered:
“... Most often, I don't know what to do... I don't know if I'm clicking in the right direction in relation to my needs, and things like that."

\subsection{The call-back service as a barrier to or a facilitator of healthcare}

This theme reflected experiences of the call-back service as a gateway to healthcare: how it provided possibilities but also problems for the informants in their attempts to gain access to healthcare providers.

\subsubsection{Feeling at ease and free from queuing}

Six informants were generally content with the call-back function of the call-back service. To receive information about the time point when they would be called back made them feel at ease as exemplified by this quote:

"I feel safe... I feel that I will get help."

Five of the informants reported that the call-back service helped them in seeking healthcare. Getting the call-back was mentioned as a step forward from previous systems of queuing on the telephone, which prevented them from doing other things. These five informants stated that they used the call-back service frequently and that they would keep using it. One informant described it like this:

"You are supposed to call, and then they say that they will call back at eight or nine... and it works!"

\subsubsection{Lack of resources is the problem, not the call-back service itself}

The informants stated that they were not content with the lack of doctor's appointments available and with the limited timing of open phone lines, and that these were more problematic than the call-back service itself. Here is a quote from an informant who did not experience trouble with the call-back service directly, but for whom the limited timing of open phone lines negatively affected their motivation to seek healthcare:

"That's... the problem, when you call in the morning. I called several times and ended up at the same 'place'. It was a little over eight in the morning, quarter past or half past, and then they had already closed [the service] for the day because then they had so much to do, and I don "t know how in the world they would fix it. For me it is tough."

Receiving the call-back after a longer period of time, but still on the same day, was also a complaint when it came to lack of available appointments and the limited timing of open phone lines. This is a quote from an informant who liked the call-back service but had concerns about the lack of available appointments: 
"I called, and my son was a little bit unwell... and they said that they would call at one o'clock... I had called at eight in the morning... At one o'clock they called me: 'we don't have any appointments.",

\subsubsection{Forced to seek other ways to access healthcare}

Four informants described some negative experiences of the call-back service, which made them use other ways of seeking healthcare. For example, one informant reported having changed her listing with a healthcare facility that provided drop-in appointments, mainly due to the lack of doctor's appointments available and the limited timing of open phone lines at her previous healthcare facility, but also due to difficulties with the call-back service. Booking appointments face to face at the healthcare facility and seeking care at other healthcare facilities were strategies that the four informants used rather than choosing to use the call-back service. Other options also mentioned were seeking healthcare at facilities that provide drop-in appointments, at the hospital or, occasionally, at the ED:

"So it has affected me also, because sometimes I may be forced to just go directly to the hospital or to the clinic without booking an appointment."

\subsection{Adjustments to the call-back service}

This theme captured the informants' suggestions as to how they would want to change and improve the existing callback service, based on their personal experience of using it.

\subsubsection{Wanting to speak to a person, not to a machine}

All informants shared their ideas on changes and improvements to the call-back service and also on how access to healthcare facilities should be adjusted for users. It was often suggested that there should be a possibility of speaking directly to a person when calling the healthcare center rather than being forced to use the call-back service. Even though the service includes a live person calling back, the navigation of the interactive system made four informants feel insecure. These informants felt that, by speaking immediately to a person, they would be more at ease regarding their healthcare needs and they would be more certain that they would get the healthcare needed:

"It is reassuring that... now they know... I have left a message, someone will get back to me and then they know who I am, maybe."

Two informants stated that personal contact was important, especially those who did not really like the call-back service:

"It would be better to speak to a person who picks up the phone and answers: 'Hello, what do you need help with?'”

Published by Sciedu Press

\subsubsection{Improvement of access to healthcare using addi- tional options}

Four informants stated that they would like to have different alternatives as to how they could book their appointments, such as booking face to face at a reception desk. Four of the informants said that they would prefer to queue on the phone instead of being called back; this was mostly related to phone lines often being closed and the unavailability of doctor's appointments. Here is a comment from one informant who preferred to book appointments face to face at the healthcare facility:

"I try ways other than calling if there is any possibility, for example, by taking a walk there to book."

Two informants stated that the healthcare facilities often only had the phone lines open during particular times in the morning. Prolonging the length of time that the phone lines would be open for individuals to call was described as a factor that could improve access to healthcare. Here is a comment from an informant who was unhappy with the hours currently provided:

"The time just... there is not enough time."

The informants described drop-in services as being a great additional alternative, providing care when needed and when pre-booked appointments were not available. Another practical suggestion by the informants was that the call-back service should include a feature that gave them the possibility of leaving a voice message together with their numerical information. In that way, the professional calling them back would know something in advance about their reason for calling, and possibly recognize them from their previous contacts with the facility. This would reduce the amount of stress, according to the informants.

\section{Discussion}

\subsection{Discussion of the findings}

Six informants viewed the call-back service in a rather positive light. The informants in this study were more often negatively affected by the lack of resources, mainly the unavailability of doctor's appointments and the closed phone lines than by the call-back service itself. However, for two informants with limited language skills and memory problems the call-back service created barriers to healthcare access. These findings suggest that for immigrants and for the elderly, both vulnerable groups with regard to health, the current call-back service might not be optimal. This is in line with previous studies from the U.K., suggesting that older patients and patients with English as an additional language were disadvantaged regarding telephone access to health care. ${ }^{[17,18]}$ Implementation of other languages in the call-back service 
could facilitate more equal access to healthcare.

Another problem mentioned by the informants was that the time allowed for dialling of numbers and choosing directions was too short; the call ended if numerical information was not provided within the permitted time frame. Research has already shown that individuals who experience trouble with telephone access are more likely to do nothing ${ }^{[5]}$ and run the risk of developing increased health problems, or to visit the ED for non-emergency issues. As in the present study, Dulude (2002) described the problems of users in managing confusing telephone systems with a multiple-choice function, where younger and older informants alike had trouble with directions that were too fast or too complicated. ${ }^{[19]}$

Our results suggest that the call-back service is useful, but it can negatively affect certain groups in society. Larger studies could explore whether additional options to seek healthcare can increase equality and lead to more appropriate use of healthcare facilities. However, attempts to evaluate new provisions of health care and flexible ways to access health care (such as walk in centers and direct phone lines for urgent care) suggested little evidence of cost benefit. ${ }^{[20]}$ The evaluation showed that it was difficult to change people's perceptions about where and how to seek care. With complex systems, there is risk for increased demands and that different providers deliver overlapping care. ${ }^{[20]}$

Informants reported postponing calls, going to the healthcare facility for drop-in appointments, or even going to the ED for non-emergency treatment. These results are similar to results reported from another study. ${ }^{[5]}$ Improvements in the call-back system may improve access to primary care. Increased use of primary care may also benefit the EDs, where nonurgent reasons for seeking care are common. ${ }^{[3,4]}$

The lack of available doctor's appointments and the closed phone lines were frequent complaints in this study. This increases the risk of not getting the care stipulated under Swedish law. ${ }^{[21]}$ A lack of healthcare appointments has been reported in other studies to be one of the greatest problems regarding barriers to healthcare access. ${ }^{[4,22]}$ It is likely that this would affect informants' opinions of the call-back service, and could change their behavior when seeking healthcare.

The desire to speak to a person was one reason why four informants turned to drop-in facilities or booked their appointments face to face, even though it meant queuing. This suggests that there is also a need to offer the possibility of booking appointments through ordinary telephone contact, or by visiting the healthcare centre. Since there are, to our knowledge, no published cost evaluations of call-back services, the increased cost of optional contact with a live person is difficult to estimate. In comparison, studies on nurse-led telephone triage suggest clinical safety and patient satisfaction, with similar costs to standard management, ${ }^{[23]}$ uncertain cost effectiveness and negligible impact on visits to EDs. ${ }^{\text {[24] }}$ Given recent issues with limited access to health care due to failures with the call-back service, ${ }^{[25-27]}$ the cost of implementing the option of calling to a health care professional should be weighed against the consequences of postponed appointments and potentially delayed diagnoses. ${ }^{[28]}$

The call-back service is meant to help users at both ends, the personnel and the individuals seeking care. ${ }^{[7]}$ Our results suggest that there are individuals in need of care who postpone their calls to healthcare, do not make them at all, or go to the ED due to problems related to the call-back service. This is unfortunate, as it would benefit everyone to provide a call-back service that facilitates equal access to healthcare for all.

Human rights covenants describe how access to care should be equal for all individuals. ${ }^{[29,30]}$ The AAAQ (Availability, Accessibility, Accountability, and Quality) framework describes how the universal right to health, in all forms and at all levels, is to be implemented. ${ }^{[31]}$ Concentrating on accessibility, it is described as having four overlapping dimensions: non-discrimination, physical accessibility, economic accessibility, and information accessibility. ${ }^{[31]}$ Our results indicate that the present Swedish call-back services may reduce some patients' access to healthcare via telephone, and may limit access to information.

When planning healthcare, it is important to adjust systems to the needs of each specific context. Socioeconomic positions, languages, diseases and disabilities, health literacy, cultural norms, religion, and age are all factors that need to be considered when access to healthcare is being discussed and planned. ${ }^{[31]}$ Another important factor is gender, since there are reported gender gaps in patient accessibility in Europe. ${ }^{[32]}$ To be able to provide equal access to healthcare, we suggest that healthcare providers should consider offering several different possibilities to seek health care. Different options for communication is important in the development of new technologies to allow fuller participation. ${ }^{[33]}$ The current interactive response systems have rigid interface and are not dynamic in nature: all users are attended to the same ways irrespectively of their navigation skills and willingness to use automated systems. ${ }^{[34]}$ Adjustments to the call-back service such as providing the option of leaving a message, of waiting on the phone to speak to someone, and of being able to go back within the multiple-choice function are potential ways to try and improve access to healthcare.

With increased globalization and migration, the call-back ser- 
vice will probably require adjustments. ${ }^{[35]}$ This pilot study provides an initial understanding of how patients, of which some had Swedish as additional language, perceived the callback service. Our results can inspire to the planning and design of larger qualitative and quantitative studies of the service, to develop adjustments which promote and provide more equal opportunities for healthcare seeking.

\subsection{Strengths and limitations}

The qualitative approach enabled unanticipated content in the informants' comments to emerge, for example, their suggestions as to how the call-back service could be improved. The themes were discussed within the multidisciplinary research team, during earlier and later stages of the study, which improved validity. ${ }^{[36]}$ One strength was that we were able to recruit informants with immigrant backgrounds and individuals who were possibly vulnerable to barriers to healthcare access, which would provide a wider range of individual experiences of the call-back service.

The major limitation of the study was the small sample size, which was linked to the high dropout rate for potential informants. Although small, our sample was purposive in helping us to gain a deeper understanding of using the call-back service at the individual level, and in revealing relevant issues of individuals potentially vulnerable to healthcare access barriers. Another limitation was that this study recruited informants from within healthcare facilities, which could have caused bias, given that individuals who did not manage to seek care were left out. Having only one male informant means that our results do not represent male experiences sufficiently.

Language skills among two of the informants were also a limitation in this study. This could lead to a loss of meaning of words, both during interviews and in the analysis process. The interviewer approached this by summarizing her interpretation back to the informant several times during the interview, to facilitate a shared understanding of the descriptions.

The call-back service as a barrier to care has not been studied in Sweden, in spite of these systems being widely implemented. Previous research has shown that access barriers increase the risk of non-urgent visits to EDs, ${ }^{[3,4]}$ so the use of EDs as a substitute for primary care due to problems related to the call-back service would be of interest to study more in detail in future research.

\section{Conclusions}

In this small, explorative study, informants seeking health care experienced that the call-back service often worked well and was useful as a means to contact health care. Negative experiences related to language barriers, time issues and lack of resources frustrated four informants and affected their healthcare-seeking behavior. Adjustments, such as language selection and a longer time frame for calls, could potentially improve the call-back service. We suggest that adjustments can be planned in collaboration with different patient groups. Findings from the present study can be used to generate future hypotheses, or to explore experiences of call-back services in other, more varied samples.

\section{ACKNOWLEDGements}

We thank the informants for sharing their views and experiences with us. We also want to thank the personnel at Angered Hospital and Närhälsan Angered rehabilitation center for helping us to recruit informants.

\section{CONFLicts OF InTEREST Disclosure}

The authors declare they have no conflicts of interest.

\section{REFERENCES}

[1] Balaj M, Huijts T, McNamara CL, et al. Non-communicable diseases and the social determinants of health in the Nordic countries: Findings from the European Social Survey (2014) special module on the social determinants of health. Scandinavian Journal of Public Health. 2017; 45(2): 90-102. PMid: 28128015. https://doi.org/10.1177/1403494816686026

[2] Myndigheten för vård- och omsorgsanalys [Swedish Agency for Health and Care Services Analysis]. Vården ur befolkningens perspektiv 2016 - en jämförelse mellan Sverige och tio andra länder 2016. [cited 201727 January]. Available from: www .vardanalys.se/ra pporter/varden-ur-befolkningens-perspektiv-2016/

[3] May M, Brousseau DC, Nelson DA, et al. Why Parents Seek Care for Acute Illness in the Clinic or the ED: The Role of Health Liter- acy. Academic Pediatrics. 2018; 18(3): 289-296. PMid: 28625711. https://doi.org/10.1016/j.acap.2017.06.010

[4] Sachs CJ, Yu CK, Nauka PC, et al. Systems Opportunities to Reduce ED Crowding From Nonemergency Referrals. American Journal of Medical Quality. 2018; 33(1): 37-42. PMid: 28693337. https://doi.org/10.1177/1062860617700721

[5] Locatelli SM, LaVela SL, Talbot ME, et al. How do patients respond when confronted with telephone access barriers to care? Health Expectations. 2015; 18(6): 2154-63. PMid: 24612441. https://doi.org/10.1111/hex.12184

[6] De Groot RA, De Haan J, Bosveld HE, et al. The implementation of a call-back system reduces the doctor's workload, and improves accessibility by telephone in general practice. Family Practice. 2002; 19(5): 516. PMid: 12356705 . https://doi.org/10.1093/famp $\mathrm{ra} / 19.5 .516$ 
[7] Teleq A. Återuppringning ger nöjdare kunder och effektivare kundservice [More satisfied customer and effective customer support with call-back]. Homepage. [cited 10 June 2018].

[8] Macinko J, Starfield B, Shi L. The Contribution of Primary Care Systems to Health Outcomes within Organization for Economic Cooperation and Developement (OECD) Countries, 1970-1998. Health Services Research. 2003; 38(3): 831-65. PMid: 12822915. https://doi.org/10.1111/1475-6773.00149

[9] Stokoe E, Sikveland RO, Symonds J. Calling the GP surgery: Patient burden, patient satisfaction, and implications for training. British Journal of General Practice. 2016; 66(652): e779-e785. PMid: 27528710. https://doi.org/10.3399/bjgp16X686653

[10] Paddison CAM, Abel GA, Roland MO, et al. Drivers of overall satisfaction with primary care: Evidence from the English General Practice Patient Survey. Health Expectations. 2015; 18(5): 10811092. PMid: 23721257. https://doi.org/10.1111/hex.12081

[11] Porter ME. A Strategy for Health Care Reform - Toward a ValueBased System. The New England Journal of Medicine. 2009; 36(2): 109-12. PMid: 19494209. https://doi.org/10.1056/NEJMp0 904131

[12] Braun V, Clarke V. Using thematic analysis in psychology. Qualitative Research in Psychology. 2006; 3(2): 77-101. https://doi .or g/10.1191/1478088706qp063oa

[13] Braun V, Clarke V. Successful Qualitative Research: A practical Guide for Beginners. London SAGE Publications; 2013.

[14] Malterud K. Qualitative research: standards, challenges, and guidelines. The Lancet. 2001; 358: 483-8. https://doi.org/10.101 6/S0140-6736(01)05627-6

[15] Samhällsanalys och statistik [Social analysis and statistics]. Göteborgsbladet 2015 - områdesfakta: Göteborgs stadsledningskontor; 2015 [cited 201730 January]. Available from: http: //statistik.goteborg.se/Global/Faktablad/G\%C3\%B6te borgsblad/GbgBlad2015/G\%C3\%B6teborg_SDN\%202015.pdf

[16] Brinkman S, Kvale S, Brinkman S. InterViews: Learning the craft of qualitative research interviewing. 3rd ed. SAGE Publications Inc.; 2014. https://doi.org/10.1007/978-1-4614-5583-7_161

[17] MacKichan F, Brangan E, Wye L, et al. Why do patients seek primary medical care in emergency departments? An ethnographic exploration of access to general practice. BMJ Open. 2017; 7(4). PMid: 28473509. https://doi .org/10.1136/bmjopen-2016-01381 6

[18] Knowles E, O'Cathain A, Turner J, et al. Awareness and use of a new urgent care telephone service, NHS 111: Cross-sectional population survey. Journal of Health Services Research and Policy. 2014; 19(4): 22-230. PMid: 24819379. https://doi.org/10.1177/135581 9614535571

[19] Dulude L. Automated telephone answering systems and aging. Behaviour \& Information Technology. 2002; 21(3): 171-84. https : //doi.org/10.1080/0144929021000013482

[20] Tan S, Mays N. Impact of initiatives to improve access to, and choice of, primary and urgent care in the England: A systematic review. Health Policy. 2014; 118(3): 304-315. PMid: 25106068 https://doi.org/10.1016/j.healthpol.2014.07.011

[21] Sveriges Kommuner och Landsting [Swedish Association of Local Authorities and Regions]. Väntetider i Vården. 2017 [cited 30 January 2017]. Available from: www . vantetider. se/veta-mer/var dgaranti/

[22] D'Avolio DA, Strumpf NE, Feldman J, et al. Barriers to primary care: perceptions of older adults utilizing the ED for nonurgent visits.
Clinical Nursing Research. 2013; 22(4): 416-31. PMid: 23624569. https://doi.org/10.1177/1054773813485597

[23] Campbell JL, Fletcher E, Britten N, et al. The clinical effectiveness and cost-effectiveness of telephone triage for managing same-day consultation requests in general practice: A cluster randomised controlled trial comparing general practitioner-led and nurse-led management systems with usual care (the ESTEEM trial). Health Technology Assessment. 2015; 19(13): 1-212. https://doi.org/10.3310/ hta19130

[24] Ismail SA, Gibbons DC, Gnani S. Reducing inappropriate accident and emergency department attendances: A systematic review of primary care service interventions. British Journal of General Practice. 2013; 63(617): e813-e820. PMid: 24351497. https: //doi.org/10.3399/bjgp13X675395

[25] Västra Götalandsregionen, Närhälsan. Problem med telefonsystem [Problems with telephone system]. 5 March 2018 [cited 10 June 2018]. Available from: http://news.cision.com/se/narhals $\mathrm{an} / \mathrm{r} / \mathrm{problem}$-med-telefonsystem, c2465069

[26] Aftonbladet. Stora problem hos Tele2 [Huge problems at Tele2]. 5 March 2018 [cited 10 June 2018]. Available from: https://www . aftonbladet.se/nyheter/a/zLkz1v/stor a-problem-hos-tele2

[27] Corren. Lång väntan på kontakt med vårdcentral [Long waiting time to get in contact with health care center]. 11 December 2016 [cited 10 June 2018]. Available from: http://www. corren. se/nyheter/mjolby/lang-vantan-p a-kontakt-med-vardcentral-om4377117.aspx

[28] Smith P, Leach J. Improving telephone access to general practice reduces time to diagnose cancer. British Journal of General Practice. 2014; 64(628): 564. PMid: 25348974. https ://doi .org/10. 339 9/bjgp14X682225

[29] World Health Organization. Basic Documents. Constitution of the World Health Organisation Geneva, Switzerland: World Health Organisation; 2009. 1-18 p.

[30] United Nations General Assembly. Universal Declaration of Human Rights: United Nations. 1948 [cited 2 March 2017]. Available from: www. ohchr.org/EN/UDHR/Documents/UDHR_Translati ons/eng.pdf

[31] United Nations Economic and Social Council. General Comment No. 14: The Right to the Hightest Attainable Standard of Health (Art. 12 of the Covenant). 2000 [cited 2 March 2017]. Available from: www.refworld.org/docid/4538838d0.html

[32] Portela C, Fernandes AC. Gender and healthcare accessibility in Europe. Journal of Hospital Administration. 2014; 3(6): 163-173. https://doi.org/10.5430/jha.v3n6p163

[33] Hanson EK, Goldhammer E, Bethard T. Telephone talk: effects of two access methods on phone call success. AAC: Augmentative and Alternative Communication. 2016; 32(3): 219-226. https : //doi.org/10.1080/07434618.2016.1205132

[34] Inam IA, Azeta AA, Daramola O. Comparative analysis and review of interactive voice response systems. In: 2017 Conference on Information Communication Technology and Society, ICTAS 2017 Proceedings: 2017. 2017.

[35] American Public Health Association. What is Public Health? 2017 [cited 4 April 2017]. Available from: https://www.apha.org/w hat-is-public-health

[36] Alhojailan MI. Thematic analysis: A critical review of its process and evaluation. West East Journal of Social Sciences. 2012; 1(1): 3947. https://scholar.google.com/citations?user=iw6gL3 MAAAJ $\& h l=e n$ 